\title{
GENETIC TRANSFORMATION OF CARROT (DAUCAS CAROTA L.) TO EXPRESS HEPATITIS B SURFACE ANTIGEN GENE FOR EDIBLE VACCINE OF HBV
}

\author{
S. Ilyas ${ }^{1}$, N. Asghar ${ }^{1}$, N. Munir ${ }^{1}$, M. Aftab ${ }^{1}$ and S. Naz ${ }^{*}$ \\ ${ }^{1}$ Dept. of Biotechnology, Lahore College for Women University, Lahore, Pakistan. \\ *Corresponding author e-mail: drsnaz31@hotmail.com
}

\begin{abstract}
Pakistan is considered as endemic to hepatitis viruses, particularly hepatitis B virus (HBV). Though vaccine against HBV is available but is still spreading in developing countries because of the various socioeconomic conditions. Therefore developing of edible vaccine is a good approach to target the spread and control of such deadliest viruses particularly in developing countries. Various fruits or vegetables can be used for production of edible vaccine. Here we are using carrot as it is much economical as compared to many fruits with greater shelf life and can be consumed without any processing. The current study was done after realizing the high transformation rates centered on strain and cultivar selection reporting a highly efficient protocol to transform carrot seedling exploiting direct somatic embryogenesis of carrot to give high transient expression of protein. In vitro grown disease-free healthy carrot plants were employed and transferred to MS medium with $1 \mathrm{mg} / \mathrm{l} \mathrm{BAP}$ and $0.5 \mathrm{mg} / \mathrm{l} 2,4-\mathrm{D}$. The surface antigen $S$ gene of Hepatitis B Virus, a potential antigen for production of antibodies by the immune system was acquired from native genotype of HBV and cloned in vector pCAMBIA 1301. This construct was introduced into Agrobacterium tumefaciens and transformed to local carrot cultivars. The transformation efficiency of HBsAg gene was upto $52 \%$ in one carrot cultivar that proved to be highest values reported till date. Hence, carrot cultivar offers promising prospects for production of economically viable and efficient anti-HBV vaccine. This study laid the basis for the development of a novel edible vaccine for hepatitis B in Pakistan that could be administered orally and especially in carrot which is essential vegetable crop grown widely.
\end{abstract}

Key words: Agrobacterium-mediated transformation, Hepatitis B surface antigen, Daucus carota, Edible vaccine, Somatic embryogenesis

https://doi.org/10.36899/JAPS.2020.5.0144

Published online June 25, 2020

\section{INTRODUCTION}

Hepatitis B virus (HBV) infection is a serious global health problem and is an important cause of liver cirrhosis and hepatocellular carcinoma. Approximately 350-400 million people worldwide are infected with HBV (Amjad et al. 2019). The patients with HBV infection are found across the globe including USA, but the issue is its high prevalence in certain regions (Mast et al. (1999); World health organization 2014). HBV infection rate is very high in underdeveloped and developing countries like Pakistan with almost 9 million people infected with this virus (Masood et al. 2019).

Although parenteral vaccination has been introduced for prevention of $\mathrm{HBV}$, but there is still alarming increase of the disease in developing countries due to non-availability, or no immune response of the commercial vaccine (Whiacre et al. 2019). HBsAg protein produced in yeast and eukaryotic systems (Saccharomyces cerevisiae, Pichiapastoris) become glycosylated which can have effect on the immune reactivity of the product (Bo et al. 2005). Furthermore, various side-effects of the vaccines are mentioned in reports as well, for example significant association between recombinant hepatitis $\mathrm{B}$ vaccine and disseminated sclerosis in patients. Vaccination with current recombinant vaccines may have a substantial rise of Hepatitis B threat within three years of immunization (Hernan et al. 2004). In addition, associations of central nervous system inflammatory de-myelination in newborn boys and administration of Engerix B vaccine is evident from studies (Mikaeloff et al. 2009).

Plant-based oral vaccines may serve as an incredible tool for mass immunization as they are lowcost, heat-stable, circumvents the cold chain requirement, and evades the need of trained healthcare personnel (Christopher et al. 2017). Mucosal vaccines also induce humoral response involving antibody production, secretory IgA, and cell-mediated immunity. Furthermore, plant-based systems ensure the stability of the protein expression, as the extent of the oligosaccharides fragments inserted post-translationally to $\mathrm{HBsAg}$ in higher eukaryotes is much less than that in yeast and other eukaryotes (Sae and Young 2017; Kim et al. 2004).

Transformation is considered as the fundamental technique for the production of viral antigens in the plants. Transformation in monocotyledons compared to dicots is still difficult when using Agrobacterium- 
mediated transformation method. Though transformation in dicot is laborious, carrot is considered as an archetypal organism for the in vitro embryogenesis (Yau et al. (2008). A good target for transformation should be able to store soluble proteins in high concentration (Deineko et al. 2009). Therefore, carrot is considered as a potential plant for production of edible vaccine as it can store 1.0$2.3 \%$ of soluble proteins in different cultivars (Luchakivskaya et al. 2011). Also because of their fast growing capability, relative ease of transport and storage, heat stability, easy to be consumed as raw, boosting of immune response due to high vitamin A content and eliminating purification requirements, carrots are best suitable for production of edible vaccines (Ranganath, 2016). Carrots have been used in previous studies to generate therapeutic proteins like diabetes associated auto-antigen (Porceddu et al. 1999) HBsAg (Imani et al. 2002), Mycobacterium tuberculosis MPT64 protein (Rosales-Mendoza et al.2007) Taeniasolium cysticercosis peptides (Sciutto et al. 2002) measles virus hem agglutinin (Bouche et al. 2003; Porceddu et al. 1999), B subunit of $E$. coli heat-labile enterotoxin (LTB), Mantigen of hepatitis B virus (Deneko et al. 2009) and human interferon alpha-2b protein (Luchakivskaya et al. 2011).

The study was designed to optimize the efficient protocol for transformation of the carrot hypocotyls for the expression of HBsAg gene which can be potentially used as edible vaccine. Carrot hypocotyls were first transformed with a gus-Int gene construct, which was used to optimize the performance of the system. Then, HBsAg gene was incorporated with efficacy in the light of experience gained in that model system. The HBsAg protein was expressed in carrot plants, especially in edible roots obtained by regeneration of somatic embryos.

\section{MATERIALS AND METHODS}

Plant Material: In vitro grown disease-free healthy carrot plants were employed for the study. Carrot seeds of local cultivars Deep Red (DR), Long Red (LR), and LTR-476 were procured from Punjab Seed Corporation, Lahore. The procedure was carried out for surfacesterilization of seeds by keeping them in ethanol $(70 \%)$ for 30 seconds followed by disinfection with $30 \%(\mathrm{w} / \mathrm{v})$ commercial bleach (sodium hypochlorite) and then rinsing was done for at least 5 times with autoclaved distilled water. These seeds were sprouted in sterilized water soaked cotton covered with filter paper and kept at $28^{\circ} \mathrm{C}$ in dark for 7-10 days to obtain cotyledonary regions. All the experiments were done in Plant Biotechnology Lab, Biotechnology Department, Lahore College for Women University.
Pre-culture of Explants: Carrot seedlings were transferred to Murashige-Skoog, (1962) medium plus 1.0 $\mathrm{mg} / 1$ BAP (6-benzylaminopurine) and $0.5 \mathrm{mg} / 1$ 2, 4- D (2, 4 - dichlorophenoxy acetic acid), $\mathrm{pH}$ adjusted to 5.7-5.8 and $0.8 \%$ agar, incubated at $25^{\circ} \mathrm{C}$ in cool fluorescent light $(11000 \mathrm{lux}, 16 \mathrm{~h} / \mathrm{d})$ to attain a length of $15-20 \mathrm{~cm}$ which were further used for genetic transformation.

Cloning and Sequencing of HBsAg Gene: Genomic DNA was extracted from HBV positive serum samples collected from public hospital of Lahore, using Gentra (Puregene, Minneapolis, USA) DNA isolation Kit. The DNA fragment of approx. 700bp was amplified by employing primers 5' ATGGAGAACATCACATCAGGATTCCTAGGA-3' and 5'-TTAAATGTATACCCAGAGACAAAAAGA-3'. NcoI and BstEII sites used for cloning are underlined. The cyclic PCR condition to amplify HBsAg gene were: initial denaturation of $5 \mathrm{~min}$ at $94^{\circ} \mathrm{C}$, followed by 30 amplification cycles (denaturation at $94^{\circ} \mathrm{C}$ for 45 seconds, annealing at $55^{\circ} \mathrm{C}$ for 45 seconds, elongation at $72^{\circ} \mathrm{C}$ for 90 seconds) and final extension of $10 \mathrm{~min}$ at $72^{\circ} \mathrm{C}$. Amplifications were done using Taq-polymerase mix kit (Vivantis, USA). The amplified products were resolved on $1 \%$ agarose gel using Gene JET Gel Extraction Kit (Thermo Scientific) and ligated into TA (PCR 2.1) vector (Invitrogen) constructing the intermediate $\mathrm{TA}-\mathrm{HBsAg}$ plasmid. E. coli strain DH5 $\alpha$ utilized for cloning plasmid and this cloned TA plasmid was sequenced using universal (M13) primers by Macrogen Inc. (Korea) for the complete sequence of HBsAg gene (Guan et al. 2011).

Construction of Expression Vector Systems: Agrobacterium tumefaciens strain LBA4404 harboring plant expression cassette pCAMBIA 1301 was used for the study. The sequenced HBsAg gene was sub-cloned into pCAMBIA 1301 vector (Marker Gene Technologies, M1592) by replacing the gus gene driven by CaMV35s promoter in it. pCAMBIA 1301 vector contained, hygromycin resistance gene,nptII gene for kanamycin resistance and nopaline synthase (nos) terminator. TDNA region of the expression cassette was engineered to have HBsAg gene sequence with adequate restriction sites (NcoI and BstEII), Histidine (His) tags, Xa factor and Kozzak sequence as shown in Fig.1. The other vector system employed $A$. tumefaciens strain EHA101 harboring a standard binary vector pZY102 that has the reporter (gus-Int) gene including intron driven by $35 \mathrm{~S}$ CaMV promoter, the herbicide selection gene of phosphinothricin acetyl transferase (bar), nptIIgene and tobacco etch virus translational enhancer (TEV) (Frame et al. 2002). The carrot (Daucas carota L.) transformation variables were standardized by using this system as the reporter gene in vector indicated the transformed plants visually through GUS assay. 
Agrobacterium-Mediated Transformation of Carrot: One colony of Agrobacterium including the plasmid was utilized for inoculation of liquid LB (Lauri- Bertani) medium $(50 \mathrm{ml})$ fortified with appropriate antibiotic like $50 \mathrm{mg} / \mathrm{l} \mathrm{kanamycin}$ sulfate, and cultures were incubated on a rotary shaker at $250 \mathrm{rpm}$ and $28^{\circ} \mathrm{C}$ overnight. Then at room temperature, centrifugation was carried out at $3000 \mathrm{~g}$ for 15 minutes. The supernatant was discarded and the pellet was re-suspended to a density range of $\mathrm{OD}_{600}=$ $0.2-0.4$ in $1 / 10^{\text {th }}$ of MS media supplemented with 100 , 150 and $200 \mathrm{mM}$ acetosyringone. Sterile petioles and hypocotyls were sliced about 5 to $10 \mathrm{~mm}$ segments with the help of fine and sharp scalpels, wounded by means of sterile needle, and inoculated in the Agrobacterium suspension (infection medium) in a falcon tube and incubated for half an hour with gentle shaking. After draining of suspension, the explants of carrot were blotted dry on sterile papers and placed for co-cultivation on MS+2,4- D $1.0 \mathrm{mg} / 1$ medium. About thirty explants were co-cultivated for two to three days in the dark (Table 1).

Selection of Transformants: Infected explants were subsequently rinsed in sterile $\mathrm{H}_{2} \mathrm{O}$, blotted dry, and incubation was done on MS medium supplemented with $1 \mathrm{mg} / \mathrm{l} \mathrm{2}$, 4- D, 50mg/L Kanamycin and 300mg/l Cefotaxime. Medium lacking antibiotics were used for positive controls while negative controls were with no infection of bacteria and incubated on selected medium at room temperature $\left(23 \pm 1{ }^{\circ} \mathrm{C}\right)$, white fluorescent lights (11000 lux) and with 16 hours day light. Calli were shifted to higher selected medium after 15 days in MS supplemented with $0.5 \mathrm{mg} / \mathrm{L} \mathrm{2,4} \mathrm{-D} \mathrm{with} \mathrm{appropriate}$ selective markers like 50mg/L Kanamycin, $10 \mathrm{mg} / \mathrm{L}$ Hygromycin and 300mg/l Cefotaxime (Table 1).

Regeneration through Somatic Embryogenesis: Somatic embryos initiate to appear within 4 and 6 weeks following infection, in hormone-free MS medium containing $10 \mathrm{mg} / \mathrm{l}$ Hygromycin B, 30mg/l Kanamycin and $300 \mathrm{mg} / \mathrm{l}$ Cefotaxime for regeneration. The regenerated transformed plants were sub-cultured in test tubes for shooting and rooting in media supplemented with appropriate hormones (Table 1). Then, hardening of plants in soil was conducted at $25^{\circ} \mathrm{C}$ under high humidity in environmental growth chamber with further gradual acclimatization in greenhouse at normal light and humidity levels (14,000 lux and 30\%, respectively).

及-glucuronidase Activity Assay: The histochemical expression of transformed gus gene in carrot cells was analyzed via bromo--chloro-indolyl glucuronide as substrate, defined by Jefferson et al.(1987). For GUS assay, the explants (both transformed and untransformed plants) were fixed in the fixative solutions first, then stained in $2 \mathrm{mM}$ X-Gluc solution (100 mM sodium phosphate buffer, $1.5 \mathrm{mM}$ potassium Ferrocyanide, 1.5
$\mathrm{mM}$ potassium Ferricyanide, $10 \mathrm{mM}$ ETDA, and $0.01 \%$ $(\mathrm{v} / \mathrm{v})$ Triton $\mathrm{X}-100)$. Vacuum infiltrate the solution briefly which facilitated solution penetration into the explants. Lastly, the explants submerged in staining solution were incubated overnight at $37^{\circ} \mathrm{C}$. After incubation, chlorophyll was washed out from plant tissues using methanol anhydrate.

Molecular Analysis of Transformants: Total genomic DNA was extracted from putative transformed and the control plants using a protocol modified from Doyle and Doyle (1990) and Stewart and Via (1993). The PCR reaction employed a 100ng of carrot DNA and HBsAg gene-specific primers. The PCR reaction for detection of HBsAg was performed as follows: carrot DNA (100ng), $0.2 \mu \mathrm{M}$ primers $(1 \mu \mathrm{l}), 1 \mathrm{X}$ PCR buffer $(5 \mu \mathrm{l}), 3.75 \mathrm{mM}$ magnesium chloride $(3.75 \mu \mathrm{l}), 0.15 \mathrm{mM}$ dNTPs, and Taq DNA polymerase $(5 \mathrm{U} / \mu \mathrm{l})$. Cycling conditions were initial denaturation at $94^{\circ} \mathrm{C}$ for $5 \mathrm{~min}$, then 30 cycles of amplification by denaturation at $94^{\circ} \mathrm{C}$ for $45 \mathrm{sec}$, annealing at $58^{\circ} \mathrm{C}$ for $45 \mathrm{sec}$, and extension at $72^{\circ} \mathrm{C}$ for $1.5 \mathrm{~min}$, and final extension at $72^{\circ} \mathrm{C}$ for $10 \mathrm{~min}$. The PCR products were analyzed by resolving them on $1 \%$ agarose gel stained with ethidium bromide. The PCR reaction produced a fragment of about $700 \mathrm{bp}$ in transformed plants and in positive control.

SDS PAGE: Total soluble protein content was extracted by using phenol extraction method from the transgenic plants to check the expression of HBsAg protein in those plants (Faurobert et al. 2007). SDS-PAGE was carried out to validate recombinant protein expression; using 200 $\mu \mathrm{g}$ of total proteins extracted, resolved on sodium dodecyl sulphate - polyacrylamide gel and identification was done on the basis of their size (Sambrook 2001). Protein samples extracted from transformed and untransformed (control) plants suspended in $200 \mu \mathrm{l}$ of sterile injection water were prepared for SDS-PAGE analysis. SDS-PAGE employed resolving gel (12\%) and stacking gel $(5 \%)$ which was electrophoresed at 60 volts for about half an hour. When samples entered the resolving gel the voltage was increased to 110 volts. The gel was electrophoresed for about 2 hours till the dye (Bromophenol blue) reached the end of gel stained with Coomassie brilliant blue dye for 40 minutes. After the gel was stained completely, it was kept in destaining solution (50\% methanol $+10 \%$ acetic acid) overnight to make the bands visible and the gel to become transparent.

\section{RESULTS}

Regeneration of Transformed Plants: Successful transformation was established for hypocotyls cultured in vitro, after standardizing the Agrobacterium-mediated transformation protocol (Fig. 2a-g). Somatic embryogenesis was achieved on hormone-free MS media, 
containing $10 \mathrm{mg} / 1$ Hygromycin, $30 \mathrm{mg} / 1$ Kanamycin and $300 \mathrm{mg} / \mathrm{l}$ Streptomycin, successively regenerating plants in the presence of $1 \mathrm{mg} / \mathrm{l} \mathrm{BAP}$ and $1 \mathrm{mg} / 12,4-\mathrm{D}$ after 5 weeks of infection (Table 1). Effective acclimatization of regenerated plantlets was achieved to the natural environmental conditions in the hardening process.

Histological analysis: Histological investigation of GUS activity was performed to counter check the transformation. The expression was observed in the hypocotyls, petioles and calli of $D$. carota. GUS positive blue coloration was noticed in transgenic tissues which were stained through X-Gluc reagents, while absence of blue color was noticed in control tissues. The staining patterns and intensity of blue color were not uniform and differed between transgenic lines (Fig. 2h-j). Transformation efficiency of GUS transformed plants fluctuated between 55 to $82 \%$ (Table 4 ).

PCR Analysis: Confirmation of successful transformation of HBsAg gene into plants was done by PCR analysis. PCR of total genomic DNA extracted from putative transformed and untransformed plants was performed with gene-specific primers under same PCR conditions as described above, to attain the expected bands of $700 \mathrm{bp} \mathrm{HBsAg}$ gene in transformed plants as illustrated in Fig. 3.

SDS PAGE: SDS-PAGE (12\%) detected protein expression in transgenic plants; by using $200 \mu \mathrm{g}$ of total soluble protein content, resolved on polyacrylamide gel, and identified HBsAg protein $(25 \mathrm{kDa})$ on the basis of size, as compared to the protein from control untransformed plants (Fig. 4).

Optimization of Various Plant Transformation Parameters: The Agrobacterium strain EHA101 harboring standard binary vector pZY102 was used to optimize the parameters for plant transformation protocol as the vector carried the reporter gus-Int gene and through GUS assay the protein expression can be expediently measured. The used optical densities of Agrobacterium strain had significant impact on the transformation efficiency of carrot hypocotyls. The optical densities $\left(\mathrm{OD}_{600}\right)$ 0.20, 0.25, 0.30, 0.35 and 0.40 at absorbance of $600 \mathrm{~nm}$ were used. About fifty explants were placed in each treatment. The results presented that bacterial optical density of 0.30 to 0.35 while infection and co-cultivation time periods proved to be most efficient for T-DNA transfer (Table 3 ).

Bacterial infection time characterized as percent of explants showing transient GUS activity significantly affected transformation efficiency Agrobacterium suspension in $50 \mathrm{ml}$ infection medium was used to inoculate about 50 hypocotyls in each falcon tube. Infection was carried out for three different timings (10, 20 , and 30 minutes) before they were transferred onto the co-cultivation medium. All control explants showed no GUS activity, where it was proportionally increased in transformed plants when the inoculation time with bacteria was increased. Use of 10 mininoculation time showed considerably lower transformation rates up to $7 \%$ only compared to the longer periods. Conversely, infection time of 20 and 30 minutes with bacteria did not cause any significant change in percentage of GUS expression which fluctuated between 47 and $39 \%$ respectively at 0.35 bacterial density (Table 3 ).

Infection and co-cultivation media augmented with acetosyringone considerably improved transformation rates. Three different concentrations of acetosyringone were tested; $100 \mathrm{mM}, 150 \mathrm{mM}$ and 200 $\mathrm{mM}$, using 50 hypocotyls. The efficiency of acetosyringone concentration was analyzed by blue color from GUS staining. An increasing trend in GUS expression was observed with the increased acetosyringone concentration in the medium. At $100 \mathrm{mM}$ acetosyringone, GUS expression was observed to be $18 \%$. However, highest GUS expression was recorded at $200 \mathrm{mM}$ concentration evident from $80 \%$ transformation rate (Table 2).

After infection, explants were co-cultivated with Agrobacterium for two to four days, to determine the optimum co-cultivation period for transformation. Callus formation progressed in the second week from the cocultured plants and somatic embryos formed in 4-6 weeks, regenerating shoots and roots in selection medium with appropriate antibiotics. The in vitro grown control negative plants died on the selection medium after two weeks of their sub-culture. Optimal co-cultivation period for carrot transformation was found to be $72 \mathrm{~h}$ at which transformation efficiency increased up to $82 \%$ for GUS gene. However, with the increase in co-cultivation time from $72 \mathrm{~h}$ to $96 \mathrm{~h}$ transformation rate decreased to $3 \%$ (Table 3). Thus, maximum number of HBsAg positive PCR results were obtained at $\mathrm{OD}_{600}=0.35$, infection period of $20 \mathrm{~min}$ and co-cultivation period $72 \mathrm{~h}$.

Interestingly, the highest observed GUS expression of $82 \%$ was achieved in Deep Red carrot cultivar. The same cultivar proved to be efficient for HBsAg gene expression and achieved transformation efficiency of $52 \%$ while the other two varieties had considerably lower rates of transformation. Nonetheless, LT-476 gave better results (18\%) as compared to long red variety $(8 \%)$ as shown in Table 4.

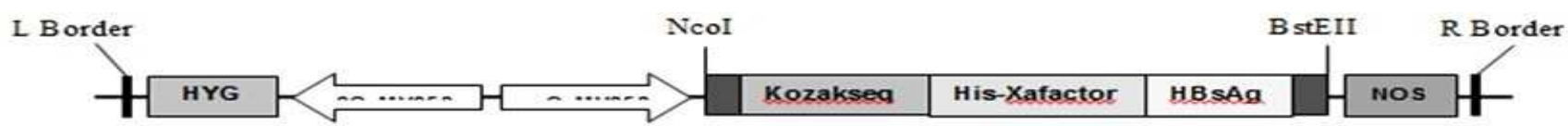

Fig. 1. T-DNA region of pCAMBIA 1301 expression cassette between left $(\mathrm{L})$ border and right $(\mathrm{R})$ border repeats 

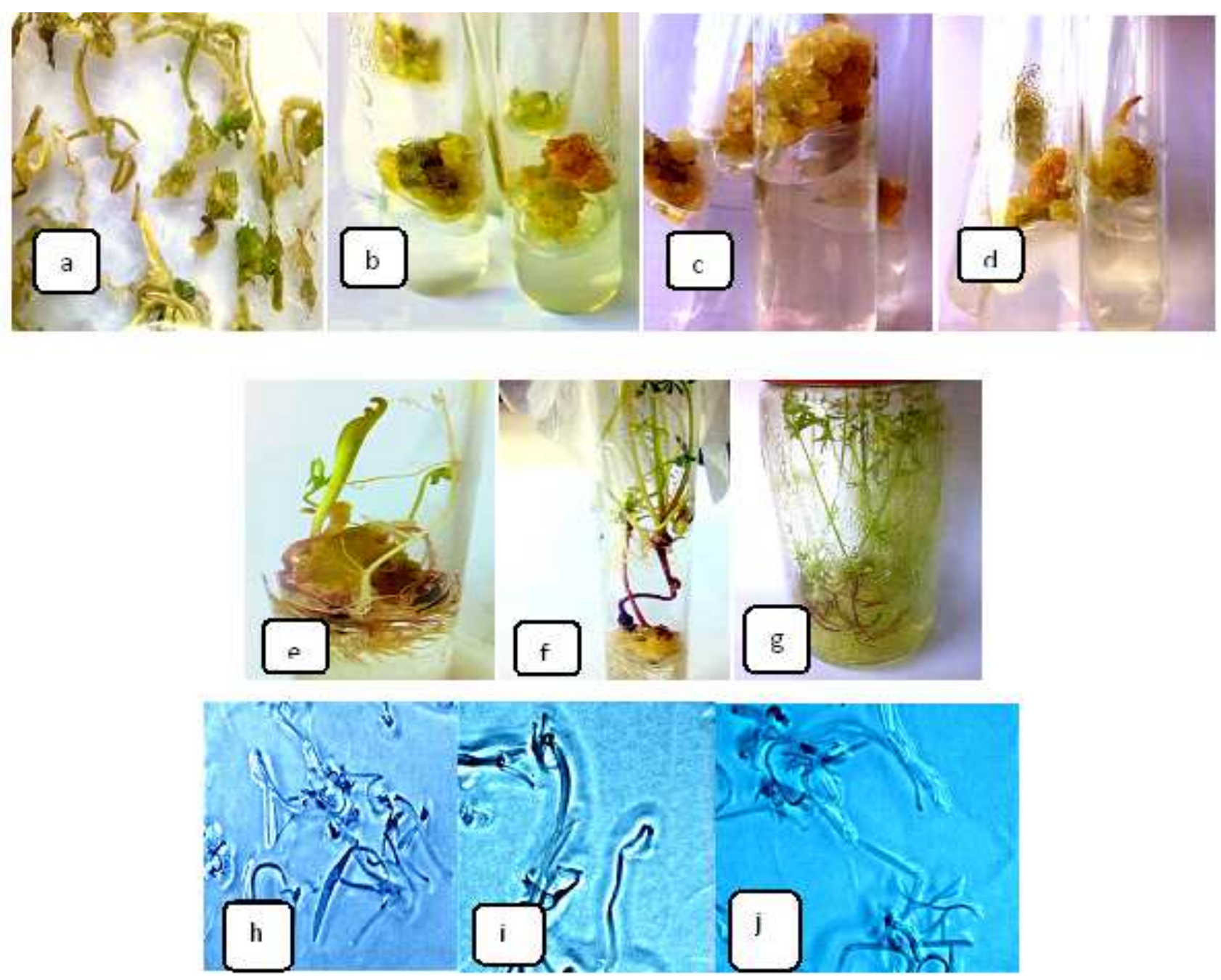

Fig. 2. a-b) Callus clones formation of selective transformants, c) Somatic embryogenesis, d-e)Regeneration, fg)Selected rooted carrot plants h)Analysis of GUS gene expression by histochemical staining of the transgenic carrot plants of different cultivars in Deep Red, i) Long Red and j) LT-476.

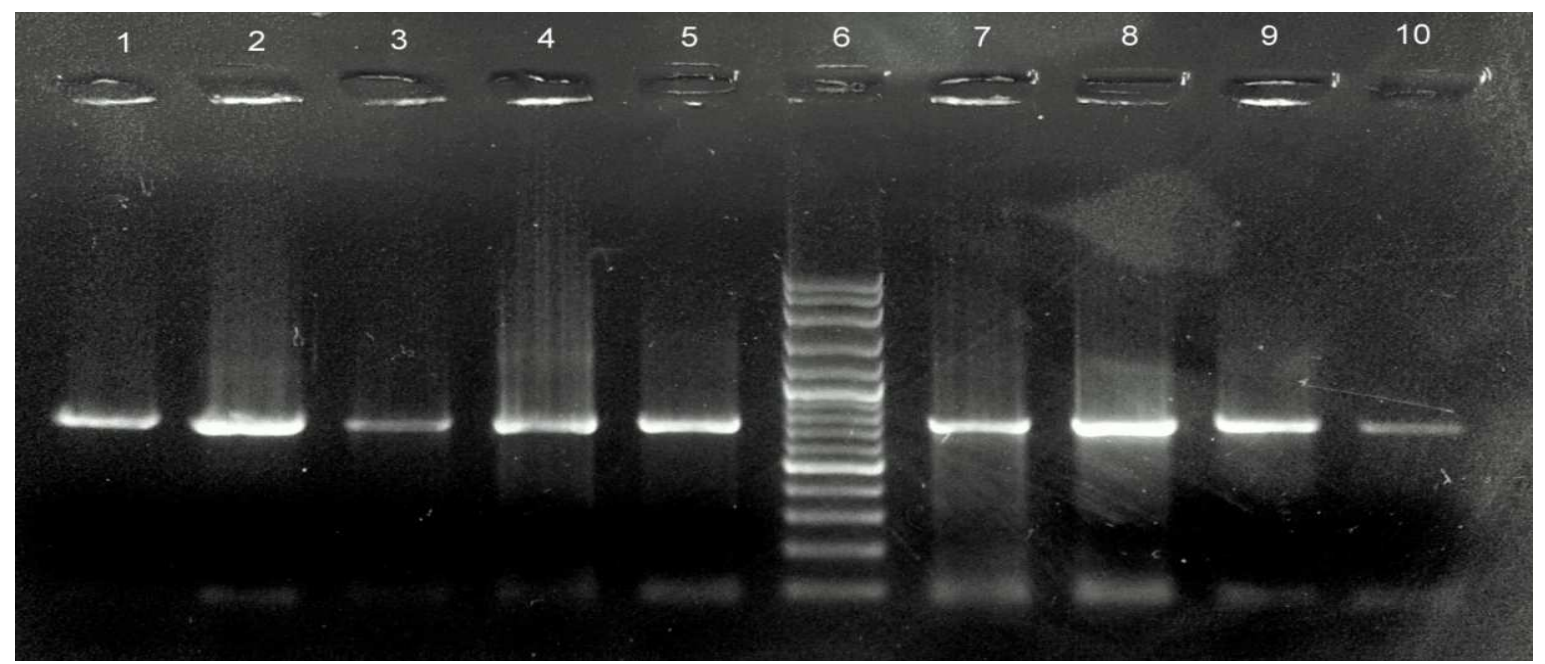

Fig.3. Electropherogram confirmed the transformation of HBsAg gene in carrot plants. 1-5 and 7-10: HBsAg gene positive plants, 6: 100bp DNA ladder. 


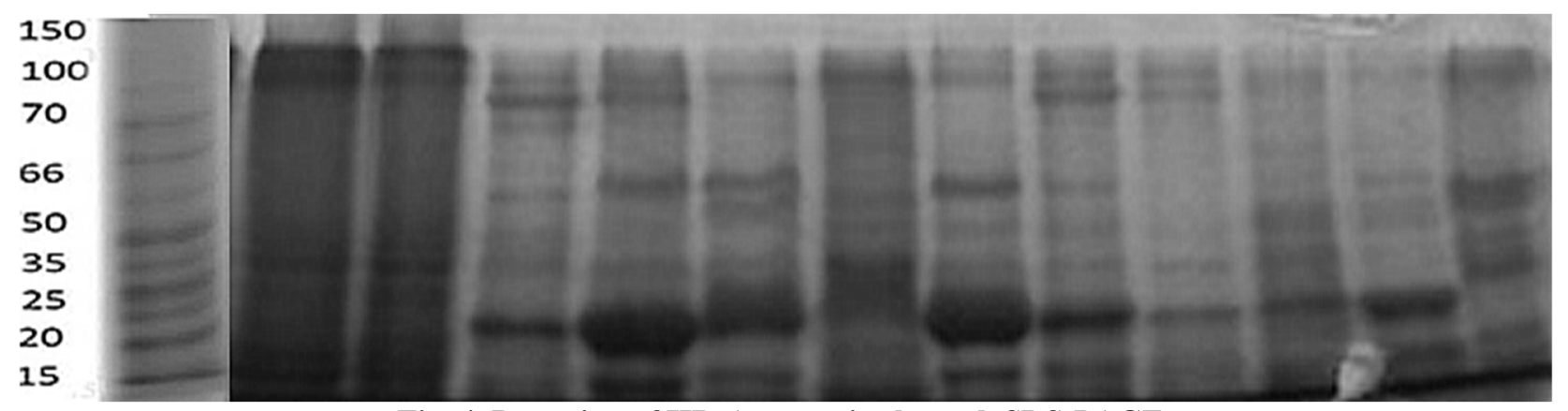

Fig. 4. Detection of HBsAg protein through SDS-PAGE.

Table 1. Media composition for various transformation and regeneration procedures.

\begin{tabular}{ccccccc}
\hline $\begin{array}{c}\text { Components of } \\
\text { Media }\end{array}$ & $\begin{array}{c}\text { Seed } \\
\text { Germination }\end{array}$ & $\begin{array}{c}\text { Pre-culture } \\
\text { Media }\end{array}$ & $\begin{array}{c}\text { Infection } \\
\text { Media }\end{array}$ & $\begin{array}{c}\text { Co-cultivation } \\
\text { Media }^{\text {Selection }}\end{array}$ & $\begin{array}{c}\text { Regeneration } \\
\text { Media }^{\mathbf{a}}\end{array}$ & \begin{tabular}{c} 
Media \\
\hline MS Salts
\end{tabular} \\
B5 Vitamins & - & $1 \mathrm{X}$ & $0.1 \mathrm{X}$ & $1 \mathrm{X}$ & $1 \mathrm{X}$ & $1 \mathrm{X}$ \\
Sucrose $(\mathrm{g} / \mathrm{l})$ & - & $1 \mathrm{X}$ & $1 \mathrm{X}$ & $1 \mathrm{X}$ & $1 \mathrm{X}$ & $1 \mathrm{X}$ \\
Agar $(\% \mathrm{w} / \mathrm{v})$ & - & 30 & 30 & 30 & 30 & 30 \\
BAP (mg/l) & 0.8 & 0.8 & 0.8 & 0.8 & 0.8 & 0.8 \\
2, 4-D (mg/l) & - & 1 & - & - & - & 1 \\
Acetosyringone (mM) & - & 0.5 & - & 1 & $1^{\mathrm{a}}$ & 1 \\
Cefotaxime (mg/l) & - & - & $200^{\mathrm{d}}$ & $200^{\mathrm{d}}$ & - & - \\
Kanamycin (mg/l) & - & - & 300 & - & 300 & 300 \\
Hygromycin (mg/l) & - & - & 50 & - & 50 & 30 \\
\hline
\end{tabular}

${ }^{\mathrm{a}}$ In the medium, 2, 4-D was tapered off over 2 weeks, ${ }^{\mathrm{b}}$ Murashige and Skoog 1962, ${ }^{\mathrm{c}}$ Gamborg et al. 1968, ${ }^{\mathrm{d}}$ Different concentrations were used, for details see table 2

Table 2. Effect of acetosyringone concentrations on transformation of carrot cv. Deep Red.

\begin{tabular}{ccc}
\hline Acetosyringone concentration $(\mathbf{m M})$ & Number of Explants & Average \% Transformation Efficiency \pm SE \\
\hline 100 & 50 & $18 \pm 1.15$ \\
150 & 50 & $44 \pm 0.58$ \\
200 & 50 & $80 \pm 2.89$ \\
\hline
\end{tabular}

Table 3.Effects of bacterial density, infection period and co-cultivation period on transformation of carrot cv. Deep Red.

\begin{tabular}{|c|c|c|c|c|c|c|}
\hline \multirow{2}{*}{$\begin{array}{l}\text { Bacterial } \\
\text { Density } \\
\left(\text { OD }_{600}\right)\end{array}$} & \multicolumn{3}{|c|}{$\begin{array}{c}\text { Average \% Transformation Efficiency } \pm \mathrm{SE} \\
\text { for Infection Period }\end{array}$} & \multicolumn{3}{|c|}{$\begin{array}{c}\text { Average \% Transformation Efficiency } \pm \text { SE for } \\
\text { Co-cultivation Period }\end{array}$} \\
\hline & $10 \mathrm{~min}$ & $20 \mathrm{~min}$ & 30 min & $48 \mathrm{~h}$ & $72 \mathrm{~h}$ & $96 \mathrm{~h}$ \\
\hline 0.20 & - & $0.67 \pm 0.33$ & $4 \pm 0.58$ & $2.6 \pm 0.33$ & $6 \pm 0.57$ & $10 \pm 1.73$ \\
\hline 0.25 & $2 \pm 0.58$ & $4.67 \pm 0.88$ & $7.33 \pm 0.88$ & $3.33 \pm 0.67$ & $8.67 \pm 0.67$ & $13.33 \pm 2.40$ \\
\hline 0.30 & $4 \pm 1.15$ & $30 \pm 2.31$ & $22 \pm 0.58$ & $8 \pm 1.73$ & $26 \pm 1.15$ & $2 \pm 0.33$ \\
\hline 0.35 & $6.6 \pm 0.33$ & $47 \pm 3.46$ & $39 \pm 1.73$ & $17 \pm 0.67$ & $82 \pm 2.02$ & $3 \pm 0.58$ \\
\hline 0.40 & $5.33 \pm 0.67$ & $1.33 \pm 0.67$ & - & $3.33 \pm 0.33$ & $1.33 \pm 0.33$ & $0.67 \pm 0.33$ \\
\hline
\end{tabular}

Number of explants-50

Table 4. Transformation efficiency using an optimized protocol for GUS and HBsAg gene harboring vectors in three carrot varieties.

\begin{tabular}{cccc}
\hline Carrot Cultivars & $\begin{array}{c}\text { Number of } \\
\text { Explants }\end{array}$ & $\begin{array}{c}\text { Average \% Transformation } \\
\text { Efficiency of pZY102 (GUS) } \pm \text { SE }\end{array}$ & $\begin{array}{c}\text { Average \% Transformation Efficiency } \\
\text { of pCAMBIA 1301 (HBsAg) } \pm \text { SE }\end{array}$ \\
\hline Deep red & 70 & $82.8 \pm 2.02$ & $52 \pm 3.46$ \\
Long red & 70 & $55 \pm 1.73$ & $8 \pm 1.73$ \\
LT-476 & 70 & $62.5 \pm 2.88$ & $17.5 \pm 2.30$ \\
\hline
\end{tabular}




\section{DISCUSSION}

In order to achieve, HBsAg production in plants, transformation was the fundamental technique to be established. High-throughput systems of transformation are among the vital technologies for advanced scientific research and genetically engineered crops production by the progress of plant genomic studies (Tian et al., 2018). Agrobacterium-mediated transformation of monocots is still comparatively a difficult technology. Though carrot being a dicot, is considered as a model organism for in vitro embryogenesis, genetic transformation of carrot is still lengthy and laborious (Yau et al.2008).

In the initial phases of our research, HBsAg gene was attained by extracting DNA from HBV carrier patients in Pakistan, so that the prevalent genotype could be utilized to formulate edible vaccine, by amplifying the $\mathrm{S}$ gene of HBsAg gene. PCR conditions of HBsAg gene were optimized by altering the concentrations of magnesium chloride in reaction mixture and also finding the optimal primer-template annealing temperature and time. To acquire pure and high yield of the desired gene, optimization of DNA amplification is essential so that non-specific products are removed (Rychlik et al. 1991). After the gene was sequenced, it was used to construct the plant expression cassette by employing all the enzymatic digestions, ligations, cell transformations and other molecular manipulations with the vector and gene, in accordance with the protocols of Sambrook and Russell (2001). The plasmid pCAMBIA 1301 was used as a shuttle vector to integrate HBsAg codons into the TDNA of $A$. tumefaciens (LBA4404).In pCAMBIA1301 construct, the GUS motif was replaced with our HBsAg gene, since it may interfere with the target protein synthesis (Sutandy et al. 2012).

Agrobacterium-mediated transformation is a complicated procedure which is affected by many parameters such as Agrobacterium strain and density (Crane et al. 2006), signal molecules like acetosyringone (Mohsen et al. 2017), infection and co-cultivation duration (Barik et al. 2005), culture media (Davis et al. 1991) and cultivar genotype (Chen et al. 2008). The TDNA delivery system from Agrobacterium to the plant cells should be well proficient to achieve a high transformation frequency (Ko et al. 2003), as transforming capabilities vary with different strains. In a recent study, the three strains of Agrobacterium tumefaciens (LBA4404, EHA105 and AGL1) used commonly for transformation were compared by performing GUS assay, and the result indicated better frequency $(21 \%)$ of LBA4404 in GUS expression (Bhattacharjee et al. 2010). Therefore, LBA4404 strain was used in the transformation experiment of HBsAG gene to plants.

Bacterial density plays a significant role in transformation process. At higher optical densities of
Agrobacterium measured by absorbance at $600 \mathrm{~nm}$, explants suffered from necrosis. There was a noteworthy linear association between the percentage of necrotic explants and bacterial concentration(Davis et al. 1991).Our results indicated that from 0.30 to $0.35 \mathrm{OD}_{600}$, the transformation efficiency increased but the significant frequency $(82 \%)$ was obtained at $0.35 \mathrm{OD}_{600}$ after $72 \mathrm{~h}$ co-cultivation period, while it declined when the bacterial concentration was increased from 0.35 to $0.4\left(\mathrm{OD}_{600}\right)$. The results were analogous to those of Punja (2005) and Saini and Jaiwal, (2007) who related that greater bacterial densities could cause hypersensitive reaction in plants. Hence, a relatively reduced inoculum concentration enhanced the transformation effectiveness and minimized the bacterial overgrowth.

Similarly, the transformation frequency was improved with the infection time increasing from 10 to $20 \mathrm{~min}$ at the bacterial density $\left(\mathrm{OD}_{600}\right)$ of 0.35 . Results showed that the 20 -min infection time generated the highest frequency of GUS positive explants (47\%) at the bacterial density of 0.35 . However, the bacterial optical density increased in the inoculation medium significantly after $20 \mathrm{~min}$ and the percentage of transformation was considerably declined to $39 \%$. The results pointed out that too short and too long infection time was not favorable for transformation as $\leq 10 \mathrm{~min}$ would be insufficient for Agrobacterium to deliver T-DNA efficiently and $\geq 30$ min would cause bacterial overgrowth which is detrimental to plants (Indurker et al. 2010).

Co-cultivation is also very important part of transformation in which bacterial adherence to plants, $\mathrm{T}$ DNA delivery and integration occurs. Co-culture outcome could be improved by augmenting some elements to the co-cultivating medium (acetosyringone) or extending co-cultivation time so that it could be completed successfully (Barik et al. 2005).In the present study, co-cultivation of $72 \mathrm{~h}$ resulted in maximum rate of transformation $(82 \%)$ at $0.35 \mathrm{OD}_{600} .48 \mathrm{~h}$ were also detected to be optimal co-culture time but as compared to $72 \mathrm{~h}$ co-cultivation, it had lower transformation efficiency. After $96 \mathrm{~h}$ co-culture period, the results indicated just 3\% efficiency that might be because of the overgrowth of $A$. tumefaciens which is harmful for the explants. Where a short time period for co-cultivation might disturbs bacterial propagation thus, decreasing its virulence resulting in lower rates of transformation.

The recalcitrant plant tissues like leaves can be transformed by stimulating the vir genes of the bacteria through signaling molecules or by co-culturing Agrobacterium with wounded plant tissue (Stachel et al. 1985). Acetosyringone or associated compounds function as signaling molecules which are known to improve the Agrobacterium-mediated transformation in many plant species. In this investigation, there was an increasing trend of transformation rate, with the increasing concentration of acetosyringone. The highest efficiency 
of transformation was achieved at acetosyringone concentration of $200 \mu \mathrm{M}$. The present outcome was in accordance with that of Padmanabhan and Sahi (2009).

Selection of transformants was based on their resistance to kanamycin and hygromycin, as our expression cassette contained these selectable marker genes. Transformed carrot cotyledonary explants showed the development of calli on the selection medium. The calli were cultured subsequently on medium without 2,4$\mathrm{D}$, tapering off its concentration so that the somatic embryogenesis progresses at phytohormone free medium, nevertheless with antibiotic selection for putative transformants. The transformed somatic embryos developed shoots and roots growing into complete plantlets on the selection medium where untransformed embryos hardly survived. The calli were transferred to a new selection medium every two weeks. Independent transgenic plantlets were obtained after about 6-8 weeks of selection.

Stable integration and expression of the transgene was determined by SDS-PAGE analysis. For this purpose protein was extracted from the recalcitrant tissues of the transformed plants and the total protein content was resolved on the $12 \%$ SDS-polyacrylamide gel with 5\% stacking gel. The resulted bands indicated the presence of $25 \mathrm{kDa}$ protein which was present in the transgenic sample but absent in the control untransformed plants. Hence, it proved stable transformation and expression of HBsAg protein in transgenic carrot plants. Previously, in transgenic carrot cells, HBsAg expression was reported to be about $25 \mathrm{ng} / \mathrm{g}$ of fresh weight (Imani et al. 2002). Thus, the HBsAg level was not greater than $\sim 0.01 \%$ of the total soluble protein content of leaf. This is insufficient level of expression for the production HBsAg in plants as bioreactors for vaccine. Further studies are required to increase the protein levels by modifying the transcriptional regulatory elements to increase the synthesis of mRNA coding for HBsAg translation.

\section{REFERENCES}

Amjad, A., J. Kumar, N. Chaudary, K. Kumar, C. M. J. Nazar and K. Khan (2019). Hepatitis B Vaccination status in chronic kidney disease: Experience at Pakistan institute of medical sciences. Cureus. 11(7):e5282.

Barik, D.P., U. Mohapatra, and P.K. Chand (2005). Transgenic grasspea (Lathyrus sativus L.): Factors influencing Agrobacterium-mediated transformation and regeneration. Plant Cell Report, 24(9):523-531.

Bhattacharjee, B., M. Mohan, and S. Nair (2010). Transformation of chickpea: Effect of genotype, explant, Agrobacterium-strain and composition of culture medium. Biolog. Planta. 54(1):21-32.
Bo, H., L. Minjian, and H. Guoqiang (2005). Expression of hepatitis B virus S gene in Pichia pastoris and application of the product for detection of anti-HBs antibody. BMB Reports, 38(6):683689.

Bouche, F.B., E. Marquet-Blouin, and Y. Yanagi (2003). Neutralising immunogenicity of a polyepitope antigen expressed in a transgenic food plant: A novel antigen to protect against measles. Vaccine, 21(17-18):2074-2081.

Chen, L., B. Zhang, and Z. Xu (2008). Salt tolerance conferred by overexpression of Arabidopsis vacuolar $\mathrm{Na}+/ \mathrm{H}+$ antiporter gene AtNHX1 in common buckwheat (Fagopyrum esculentum). Transgenic Res. 17(1): 121- 128.

Christopher, C., C. Raul, M. Johan, J.T. Maria, A.H. Andres, J. Fabiola, and C. Ibanez (2017). Disease Prevention: An Opportunity to Expand Edible Plant-Based Vaccines. Vacc. 5 (14):doi:10.3390/vaccines5020014.

Crane, C., E. Wright, R.A. Dixon, and Z.Y. Wang (2006). Transgenic Medicago truncatula plants obtained from Agrobacterium tumefaciens-transformed roots and Agrobacterium rhizogenestransformed hairy roots. Planta. 223(6):13441354.

Daniell, H., S.J. Streatfield, and K. Wycoff (2001). Medical molecular farming: Production of antibodies, biopharmaceuticals and edible vaccines in plants. Trends plant Sci. 6(5): 219226.

Davis, M.E., R. Daniel Lineberger, and A. Raymond Miller (1991). Effects of tomato cultivar, leaf age, and bacterial strain on transformation by Agrobacterium tumefaciens. Plant Cell Tiss. Org. Cult. 24(2):115-121.

Deineko, E.V., A.A. Zagorskaya, and S.G. Pozdnyakov (2009). Comparative analysis of HBV Mantigen production in leaves of individual transgenic carrot plants. Biochem. Biophys. 425: 76-79.

Doyle, J. and J. Doyle. (1990). Isolation of plant DNA from fresh tissue. Focus (Madison) 12:13-15.

Faurobert, M., E. Pelpoir and J. Chaï, 2007. Phenol extraction of proteins for proteomic studies of recalcitrant plant tissues. 4, Plant Proteomics, Humana Press. 9-14 p.

Frame, B.R., H. Shou, and R.K. Chikwamba (2002). Agrobacterium tumefaciens-mediated transformation of maize embryos using a standard binary vector system. Plant Physiol. 129(1):13-22.

Gamborg, O.L., Miller, R.A. and K. Ojima (1968). Nutrient requirements of suspension cultures of soyabean root cells. Exp. Cell Res. 50(1): 151158. 
Guan, Z.J., Guo, B., Huo, Y.L. and Y. H. Wei (2011). Morphological and Physiological characteristics of transgenic cherry tomato mutant with HBsAg Gene. Genetika. 47(8):1044-51.

Hernan, M.A., S.S. Jick, M.J. Olek, and H. Jick (2004). Recombinant hepatitis B vaccine and the risk of multiple sclerosis. Neurolog. 63(5): 838-842.

Imani, J., A. Berting, and S. Nitsche (2002). The integration of a major hepatitis B virus gene into cell-cycle synchronized carrot cell suspension cultures and its expression in regenerated carrot plants. Plant Cell Tiss. Org. Cult. 71(2):157164.

Indurker, S., H.S. Misra, and S. Eapen (2010). Agrobacterium-mediated transformation in chickpea (Cicer arietinum L.) with an insecticidal protein gene: Optimisation of different factors. Physio. Mole. Biol. Plants. 16(3):273-284.

Jefferson, R., T. Kavanagh, and M. Bevan (1987). GUS fusion: beta-glucuronidase as a sensitive and versatile gene fusion marker in higher plants. EMBO J.6 (13):3901-3907.

Kim, M.W., S.K. Rhee, and J.Y. Kim (2004). Characterization of N-linked oligosaccharides assembled on secretory recombinant glucose oxidase and cell wall mannoproteins from the methylotrophic yeast Glycobiol. 14(3):243-251.

Ko, T.S., S. Lee, S. Krasnyanski, and S.S. Korban (2003). Two critical factors are required for efficient transformation of multiple soybean cultivars: Agrobacterium strain and orientation of immature cotyledonary explant. Theoret. Appl. Genet. 107(3):439-447.

Luchakivskaya, Y., O. Kishchenko, and I. Gerasymenko (2011). High-level expression of human interferon alpha-2b in transgenic carrot (Daucus carota L.). Plants Cell Rep. 30(3): 407-415.

Marquet-Blouin, E., F.B. Bouche, A. Steinmetz, and C.P. Muller (2003). Neutralizing immunogenicity of transgenic carrot (Daucus carota L.)-derived measles virus hemagglutinin. Plant Mole. Biol. 51(4):459-469.

Masood, I., Waheed, U., Arshad, M., Saeed, M., Farooq, A., Moneeba, S., Basharat, N, and Zaheer, H.A. (2019). Molecular epidemiology of hepatitis B virus genotypes in blood donors in Islamabad, Pakistan. J Lab Physicians, 11(3):240-243.

Mast, E.E., M.J. Alter, and H.S. Margolis (1999). Strategies to prevent and control hepatitis B and $\mathrm{C}$ virus infections: a global perspective. Vaccine, 17(13-14):1730-1733.

Mikaeloff, Y., G. Caridade, S. Suissa, and M. Tardieu (2009). Hepatitis B vaccine and the risk of CNS inflammatory demyelination in childhood. Neurol. 72(10): 873-880.
Mohsen, N., Noori, S.A.S, Galuszka, P. and S.S.M. Mortazavian (2017). Tissue Culture-based Agrobacterium-mediated and in planta Transformation Methods. Czech J. Genet. Plant Breed. 53(4): 133-143.

Murashige, T., and F. Skoog (1962). A revised medium for rapid growth and bio assays with tobacco tissue cultures. Physiologia plantar. 15(3): 473497.

Padmanabhan, P.,and S.V. Sahi (2009). Genetic transformation and regeneration of Sesbania drummondii using cotyledonary nodes.Plant Cell Rep. 28(1):31-40.

Porceddu, A., A. Falorni, and N. Ferradini (1999). Transgenic plants expressing human glutamic acid decarboxylase (GAD65), a major autoantigen in insulin-dependent diabetes mellitus. Mol. Breed. 5(6):553-560.

Punja, Z.K. (2005). Transgenic carrots expressing a thaumatin-like protein display enhanced resistance to several fungal pathogens. Canadian J. Plant Pathol. 27(1): 291-296.

Ranganath, R.R. (2016). Hairy Roots Production through Agrobacterium rhizogenes Genetic Transformation from Daucus carota explants. Int. J. Adv. Res. Biol. Sci. 3(8): 23-27.

Rosales-Mendoza, S., R.E. Soria-Guerra, and M.T. de Jesus Olivera-Flores (2007). Expression of Escherichia coli heat-labile enterotoxin b subunit (LTB) in carrot (Daucus carota L).Plant Cell Rep. 26(7): 969-976.

Rychlik, W., W.J. Spencer, and R.E. Rhoads (1991). Optimization of the annealing temperature for DNA amplification in vitro. Nucleic Acid Res. 18(21): 6409-6412.

Sae, H. K., and S.J. Yong (2017). The development of mucosal vaccines for both mucosal and systemic immune induction and the roles played by adjuvants. ClinExp Vaccine Res. 6(1): 15-21.

Saini, R., and P.K. Jaiwal (2007). Agrobacterium tumefaciens-mediated transformation of blackgram: An assessment of factors influencing the efficiency of uidA gene transfer.Biol. Plant. 51(1):69-74.

Sambrook, J., and D.W. Russell (2001). Molecular Cloning: A Laboratory Manual. Cold Spring Harb Lab. Press Cold Spring Harb NY 999.

Sciutto, E., G. Fragoso, and K. Manoutcharian (2002). New approaches to improve a peptide vaccine against porcine Taenia solium cysticercosis.Arch. Med. Res. 33(4):371-378.

Stachel, S.E., E. Messens, M. Van Montagu, and P. Zambryski (1985). Identification of the signal molecules produced by wounded plant cells that activate T-DNA transfer in Agrobacterium tumefaciens. Natur. 318(6047):624-629. 
Stewart, C.N., and L.E. Via (1993).A rapid CTAB DNA isolation technique useful for RAPD fingerprinting and other PCR applications. Biotechs. 14(2): 748-750.

Sutandy, F., P.D. Utari, and T. Kristianti (2012). Transformation and Analysis of L-HBsAg DNA Transient Expression in Tobacco. J. Life Sci. Technol. 1(1): 19-24.

Tian, L., K.S. Jing, L. Zahaohua, and L. Qing (2018). Transformation of HBsAg (Hepatitis B Surface Antigen) Gene into Tomato Mediated by Agrobacterium tumefaciens. Czech J. Genet. Plant Breed. 47(2):69-77

Wang, L., D. Ni, Y. Chen, and Z. Li (2001). The expression of Mycobacterium tuberculosis MPT64 protein in transgenic carrots. Acta Bot. Sini. 43(2):132-137.
Whitacre, D.C., Peters, C.J., Sureau, C., Nio, K., Li, F., Su, L., Jones, J.E., Isogawa, M., Sallberg, M., Frelin, L., Peterson, D.L. and Milich, D.R. (2019). Designing a therapeutic hepatitis B vaccine to circumvent immune tolerance. Hum Vaccin Immunother. 6:1-18

World Health Organisation 2014. WHO Fact Sheet 204. In: WHO Fact Sheets. http://www.who.int/mediacentre/factsheets/fs20 4/en/\#.

Yau, Y.Y., S.J. Davis, A. Ipek, and P.W. Simon (2008). Early Identification of Stable Transformation Events by Combined Use of Antibiotic Selection and Vital Detection of Green. Agric Sci China. 7(6):664-671. 